\title{
Katarzyna Thiel-Janczuk, Les Mythographies mineures de Patrick Modiano. Entre le labyrinthe et le rhizome
}

\section{Elisa Bricco}

\section{(2) OpenEdition \\ 1 Journals}

\section{Edizione digitale}

URL: http://journals.openedition.org/studifrancesi/9037

DOI: $10.4000 /$ studifrancesi.9037

ISSN: 2421-5856

\section{Editore}

Rosenberg \& Sellier

\section{Edizione cartacea}

Data di pubblicazione: 1 octobre 2008

Paginazione: 490-491

ISSN: 0039-2944

\section{Notizia bibliografica digitale}

Elisa Bricco, «Katarzyna Thiel-Janczuk, Les Mythographies mineures de Patrick Modiano. Entre le labyrinthe et le rhizome», Studi Francesi [Online], 155 (LII | II) | 2008, online dal 30 novembre 2015, consultato il 13 janvier 2021. URL: http://journals.openedition.org/studifrancesi/9037 ; DOI: https:// doi.org/10.4000/studifrancesi.9037

Questo documento è stato generato automaticamente il 13 janvier 2021.

\section{cc) $($ ) $\ominus$}

Studi Francesi è distribuita con Licenza Creative Commons Attribuzione - Non commerciale - Non opere derivate 4.0 Internazionale. 


\title{
Katarzyna Thiel-Janczuk, Les Mythographies mineures de Patrick Modiano. Entre le labyrinthe et le rhizome
}

\author{
Elisa Bricco
}

\section{NOTIZIA}

KATARZYNA THIEL-JANCZUK, Les Mythographies mineures de Patrick Modiano. Entre le labyrinthe et le rhizome, Lewiston-Queenston-Lampeter, The Edwin Mellen Press, 2006, pp. 182.

1 Il saggio di K. Thiel-Ja-czuk prende in esame l'opera integrale di Patrick Modiano attraverso una prospettiva mitocritica generale accompagnata da percorsi di approfondimento incentrati su elementi tematici e strutturali, con precisi e puntuali riferimenti testuali.

2 Il mitico labirinto e il più moderno rizoma sono le figure, opposte e complementari al tempo stesso, che consentono di descrivere globalmente l'opera romanzesca di Modiano perché significano la doppia tensione che vi si esplica verso la verità e verso la mitizzazione della storia personale dell'autore. Il percorso dialettico dell'A. procede in tre tappe che partono con la descrizione dell'intera opera modianesca come messa in scena di una ricerca personale da parte dell'autore-narratore alle prese con le difficoltà causate principalmente dal momento storico che più lo ha segnato, ovvero il periodo dell'Occupazione nazista. La ricerca di un'identità si sviluppa nei romanzi attraverso la quête portata avanti dai narratori-protagonisti, alter ego e figurazioni dell'autore. A partire da questi presupposti generali, nel primo capitolo sono presentate alcune figure mitiche, come Arianna e il filo, il Minotauro, che permettono all'A. una rilettura dei romanzi attraverso la quale si mette in luce un movimento di superamento della staticità delle figure mitiche e del loro significato codificato per un ritorno a figurazioni 
più arcaiche che consentono all'autore di conciliare la realtà storica con quella personale. Così, dunque, l'infanzia si rivela un momento problematico perché è negata e corrotta a causa del periodo storico sfavorevole vissuto dai personaggi-narratori; ma proprio per questa situazione svantaggiosa essa viene anche decontestualizzata e subisce quindi un processo di mitizzazione che la rende unica e al di sopra di ogni contingenza: essa diventa materiale romanzesco.

3 Nella seconda parte sono presi in esame i luoghi e le modalità della ricerca esistenziale in un mondo disgregato dalla forza devastatrice della Storia. Il movimento, più che il labirinto, segue la forma di un rizoma, privo di centro e soggetto a una forza centripeta che spinge i personaggi in direzioni diverse. In questa nuova dinamica si attua un ritorno al mito, ovvero al ricorso a una realtà extra-temporale più autentica. L'universo diegetico subisce una decomposizione parodistica in cui sono messi in discussione gli elementi che lo caratterizzano: i personaggi hanno comportamenti assolutamente "sovversivi", imprevedibili e inconsueti che illustrano altrettanti tentativi di resistenza alle forze negative della Storia. Questa risposta "morale" dei personaggi che si oppongono alla fatalità storica è ricondotta dall'A. all'adozione da parte dello scrittore di una posizione di resistenza etica che sarebbe insita nella sua eredità famigliare.

4 La terza parte propone una riflessione sulle strutture testuali riassumibili in due movimenti che sottendono alla composizione letteraria: un percorso chiuso in cui la ricerca esistenziale si realizza nel tentativo di ricostruzione della biografia altrui, e riconducibile al modello del labirinto; un percorso aperto, sul modello del rizoma, in cui l'attività di creazione letteraria è più esplicitamente finzionale e segna un superamento dell'impasse storico-autofinzionale.

5 Le pagine conclusive del volume appaiono le più convincenti perché la prospettiva si apre su considerazioni generali nelle quali l'A. vede la narrativa di Modiano dal punto di vista di un impegno autoriale, lontano da echi sartriani, per cui la costruzione e la ricostruzione di personaggi è resa possibile proprio dal movimento di autoimplicazione dell'autore stesso nella materia testuale, quantunque lontano da ogni implicazione autobiografica e anche soltanto autoreferenziale. 